\title{
Disability, Loneliness and Health in the UK: Cross-sectional survey
}

Professor Eric Emerson, PhD (corresponding author: Cleredene, Vicarage Hill, Branscombe, Devon, EX12 fDN, UK; +44 (0)1297 680123; eric.emerson@lancaster.ac.uk) $)^{1,2,3}$

Professor Roger Stancliffe, PhD ${ }^{1,2}$

Dr Nicola Fortune, $\mathrm{PhD}^{2}$

Professor Gwynnyth Llewellyn, PhD ${ }^{1,2}$

1 Centre for Disability Research and Policy, Faculty of Health Sciences, University of Sydney, Sydney, NSW 2141, Australia

2 Centre of Research Excellence in Disability and Health, University of Sydney, Sydney, NSW 2141, Australia

3 Centre for Disability Research, Faculty of Health \& Medicine, Lancaster University, Lancaster, LA1 4YW, UK 


\section{Abstract}

\section{Background}

Recent research has suggested that exposure to loneliness can have a powerful detrimental impact on health. Addressing socially determined health inequity requires understanding of the situation of marginalised or vulnerable groups. People with disability are increasingly being recognised as one such group. Little population-based research has addressed the association between disability, loneliness and health.

\section{Methods}

Secondary analysis of data collected in waves 8 and 9 of Understanding Society, the UK's main annual household panel study.

\section{Results}

Rates of exposure to substantial loneliness were $25.4 \%(95 \% \mathrm{Cl} 23.5 \%-27.3 \%)$ among adults with persistent disability (disability at W8 and W9), 15.4\% (13.3\%-17.5\%) among adults with disability onset (disability at W9 only), $12.3 \%$ (10.1\%-14.5\%) among adults with disability offset (disability at W8 only), and 6.9\% (6.5\%-7.3\%) among adults with no disability. Exposure to loneliness was positively associated with the incidence (GHQ-12) and prevalence (SF-12MCS) of mental health problems. Disability status appeared to moderate the association between loneliness and health, with the difference between the persistent disability and no disability group increasing with exposure to greater levels of loneliness.

\section{Conclusion}

Loneliness may be an important determinant of the poorer health of working age adults with disability in the UK. Exposure rates are significantly higher than among the non-disabled population. The strength of association between exposure to loneliness and poorer mental health is greater for people with persistent disability than people with no disability. 
Keywords

Disability, Loneliness, Mental Health 


\section{Introduction}

The degree to which individuals are interconnected and embedded in communities has a powerful impact on their health.[1] Knowledge in this area is based on a range of approaches for conceptualising and measuring social connections, including social network analysis and measuring levels of social support and social isolation.[1, 2] More recently, attention has focused on the association between loneliness and health.[3-9] Loneliness has been defined primarily as an emotional state; a 'distressing feeling that accompanies the perception that one's social needs are not being met by the quantity or especially the quality of one's social relationships'.[3] Recent systematic reviews suggest that loneliness predicts future mortality,[5] impaired physical health,[8] coronary heart disease[10] and prognosis of mental health conditions.[6]

Public health interventions addressing socially determined health inequity need to take account of the situation of marginalised or vulnerable groups.[11,12] People with disability are increasingly being recognised as one such group.[12-14] Compared to the general population, people with disability tend to have fewer friends, less social support, and be more socially isolated.[14-20] Research we have previously conducted, based on a nationally representative sample of approximately 17,000 'working age' adults in England, found that people with disability were significantly more likely than their non-disabled peers to report loneliness.[21] We also reported that: (1) adjusting risk estimates to take account of between-group differences in living circumstances significantly reduced effect sizes for exposure to loneliness; (2) the prevalence of loneliness was highest among adults with disability who were younger, economically inactive, living in rented or other accommodation, living alone, and with low levels of access to environmental assets such as local shops; (3) disability and loneliness were both associated with lower personal wellbeing; and (4) there was no evidence that disability status moderated the association between exposure to loneliness and wellbeing. We do not know of any other population-based studies that have addressed the relationship between disability and loneliness. 
Disability is not necessarily irreversible or lifelong. Indeed, longitudinal research has highlighted the dynamic nature of disability, with considerable rates of disability onset and offset occurring within one year periods.[22, 23] Given this, we used data from two consecutive annual waves (8 and 9) of Understanding Society to separately identify respondents who experienced persistent disability (disability reported in both waves), disability onset (disability reported in wave 9 but not wave 8), and disability offset (disability reported in wave 8 but not wave 9), to enable more nuanced examination of the relationship between disability, loneliness and health.

Given the paucity of research in this area, our aims were:

1. To estimate the prevalence of exposure to loneliness among a nationally representative sample of adults in the UK with persistent disability, disability onset, disability offset and no disability (age range 16-64);

2. To identify personal demographic characteristics and aspects of living circumstances that may be associated with variation in exposure rates;

3. To investigate the association between loneliness and self-rated health and mental health among respondents with persistent disability, disability onset, disability offset and no disability.

\section{Method}

Secondary analysis of data collected in waves 8 and 9 of Understanding Society, the UK's main annual household panel study (https://www.understandingsociety.ac.uk/). Understanding Society is an initiative funded by the Economic and Social Research Council and various Government Departments, with scientific leadership by the Institute for Social and Economic Research, University of Essex, and survey delivery by NatCen Social Research and Kantar Public.[24] The research data are distributed by the UK Data Service. Full details of the survey's development and methodology are available in a series of publications,[25-27] key aspects of which are summarized below. 


\section{Sampling \& Procedure}

In the first wave of data collection (2009-2011), random sampling from the Postcode Address File in Great Britain and from the Land and Property Services Agency list of domestic properties in Northern Ireland identified 55,684 eligible UK households. At Wave 1, full face-to-face interviews were completed with 47,750 individuals aged 16 or older (individual response rate within participating households, 80\%). At Wave 8 (W8: 2016-18), full interviews were completed with 37,565 individuals aged 16 or older (response rate 68\%).[26, 27] At Wave 9 (W9: 2017-19), full interviews were completed with 34,959 individuals aged 16 or older (response rate 68\%).[26, 27] New individuals enter the survey if they: (a) are living in a participating household and attain the age of 16; or (b) become resident in a participating household. Individuals leave the survey if they: (a) no longer give consent to participate; (b) cannot be traced; or (c) move abroad. Data collection for variables used in the present paper was undertaken using a combination of computer-assisted personal interviewing and computer-assisted self-completion.[26, 27]

\section{Measures}

\section{Disability}

Disability was ascertained by an affirmative response to two questions. First, 'Do you have any longstanding physical or mental impairment, illness or disability? By 'long-standing' I mean anything that has troubled you over a period of at least 12 months or that is likely to trouble you over a period of at least 12 months.'

Second, if respondents gave an affirmative response to the first question, they were asked 'Does this/Do these health problem(s) or disability(ies) mean that you have substantial difficulties with any of the following areas of your life?'. The response options (all that applied were coded) were: (1) mobility; (2) lifting, carrying or moving objects; (3) manual dexterity; (4) continence; (5) hearing (apart from using a standard hearing aid); (6) sight (apart from wearing standard glasses); (7) communication or speech problems; (8) memory or ability to concentrate, learn or understand; (9) 
recognising when you are in physical danger; (10) physical co-ordination; (11) difficulties with own personal care; (12) other. Respondents who reported difficulties in one or more of these life areas were counted as having disability in that wave of the survey. Given the high degree of intercorrelation between certain categories, we recoded these functional limitation categories combining categories $1-3$ and 10 to create a general category of physical limitation. For this and the remaining categories, we created binary variables: 1 designating functional limitation in the specific life area, 0 designating no limitation. Respondents could have membership of more than one functional limitation category.

From the W8 and W9 data on disability we created a four-category variable: (0) no disability at W8 or W9; (1) disability at W8 only (disability offset); (2) disability at W9 only (disability onset); (3) disability at W8 and W9 (persistent disability). Disability data were missing for $0.1 \%$ in W8 and W9.

\section{Loneliness}

Loneliness was measured by four separate items first introduced into Understanding Society in W9. Items 1-3 were taken from a short form of the UCLA Loneliness Scale.[28] The fourth item has recently been included in UK surveys as a headline indicator for the measurement of loneliness.[29]

1. How often do you feel that you lack companionship?

2. How often do you feel left out?

3. How often do you feel isolated from others?

4. How often do you feel lonely?

Response options for all items were: hardly ever or never, some of the time, often. The four items evidenced strong internal consistency (Cronbach's alpha $=0.90$ ) and all loaded strongly on the first extracted component of an unrotated principal components analysis which accounted for $76.5 \%$ of variation. Factor scores were recoded to generate a simple ordinal scale with a distribution similar to sample responses to individual items; low loneliness (60\%), moderate loneliness (30\%), substantial loneliness (10\%). Data were missing for $2.2 \%$ of respondents. 
Health

SF-12

The SF-12 is a widely used measure of mental and physical functioning over the past four weeks with strong psychometric properties.[30-32] Scoring of the SF-12 generates two summary scores (mental functioning and physical functioning) each with a range of 0 (low) to 100 (high functioning). Data were missing for $3.1 \%$ of respondents at W9.

\section{GHQ-12}

The GHQ-12 is a widely used screening measure for the onset of common mental health problems. The 12 items are rated on a four-point scale relating to the frequency or severity of the symptom in comparison with what is usual for the respondent.[33, 34] We used the most common form of GHQ12 scoring ('caseness') which recodes item scores of 1 and 2 to 0 and 3 and 4 to 1 , and then sums scores across items to generate a scale with a range of 0 (low probability of onset) to 12 (high probability). Data were missing for $2.6 \%$ of respondents at W9.

\section{Covariates}

\section{Demographics}

Information was collected on age group in ten-year bands, gender and ethnicity (White UK/White other/Asian/Black/Mixed/Other). Age and gender data were available for all respondents. Ethnicity data were missing for $0.1 \%$ of respondents.

\section{Living Arrangements and Socio-Economic Position}

We derived a three-category indicator of current living arrangements from the available data: (1) Living alone (as only adult) in the household; (2) living as a couple with another adult in the household; (3) 'other' living arrangements (e.g., living with parents, living in a communal household). Data were missing for $0.1 \%$ of respondents. We also derived five indicators of socio-economic position (SEP): (1) Household income poverty; (2) low access to consumer durables; (3) self-reported 
financial strain; (4) home ownership; and (5) employment status. Details of these measures are presented in Supplementary Table 1.

\section{Ethical Approval}

Understanding Society is designed and conducted in accordance with the ESRC Research Ethics Framework. Ethics approval for Waves 6-8 was received via a letter dated 20th August 2013 from the University of Essex Ethics Committee and for Waves 9-11 via a Letter dated 4th October 2016 from the University of Essex Ethics Committee. At that time a system of ethics approval numbers was not in place.

\section{Approach to Analysis}

First, we provided simple descriptive measures of the prevalence of disability and loneliness at W9. Second, we estimated adjusted prevalence rate ratios (PRR) for the risk of reporting moderate and substantial loneliness among respondents in each of the three disability groups (respondents without disability being the reference group). In Model 1, we adjusted for personal demographics (age, gender, ethnicity). In Model 2 we also adjusted for living arrangements and the five indicators of SEP. PRR were estimated using Poisson regression with robust standard errors.[35] Given the small amounts of missing data, complete case analyses were undertaken on a subsample of 18,029 adults aged 16-64 (94\% of the available sample of 19,166$)$.

Third, we estimated the strength of the relationship between exposure to loneliness at W9 (independent variable) and physical and mental health at W9. We used generalized linear models in SPSS 24 with SF-12 and GHQ-12 scores as the dependent variable. Models included the following independent variables: disability status, loneliness and all covariates (measured at W9) listed in the previous section. The models also included a disability*Ioneliness interaction term to determine whether disability status moderated the association between loneliness and health. Analyses were undertaken on a subsample of 16,453 adults aged 16-64 for whom complete data were available 
(86\% of the available sample at W9). All analyses were undertaken using sample weights released with the data to account for known biases in recruitment and retention.

\section{Results}

\section{Prevalence of Disability}

In the analytic subsample $76.6 \%(95 \% \mathrm{Cl} 76.0-77.2)$ of adults reported no disability, $4.9 \%(95 \% \mathrm{Cl} 4.6-$ 5.2) reported disability offset (W8 only), $6.6 \%(95 \% \mathrm{Cl} 6.2-7.0)$ reported disability onset (W9 only), and $11.9 \%$ (95\% $\mathrm{Cl} 11.3-12.4)$ reported persistent disability (W8 and W9). The prevalence of specific functional limitations associated with disability at W9 is presented in Supplementary Table 2.

\section{Prevalence of Loneliness}

The unadjusted prevalence of loneliness among respondents with and without disability is presented in Table 1 for the derived ordinal measure of loneliness with adjusted PRRs. The highest rates of Ioneliness were observed among adults with persistent disability, followed by adults with disability onset, followed by adults with disability offset, followed by adults with no disability.

[insert Table 1]

In all adjusted models, adults with disability were at significantly greater risk of exposure to moderate and substantial loneliness. Risk for exposure to substantial loneliness was significantly greater than risk of exposure to moderate loneliness. Additionally adjusting for living arrangements and SEP (difference between Models 1 and 2) led to a 55\% reduction for risk of substantial loneliness among respondents with persistent disability, 32\% among respondents with disability onset and $42 \%$ among respondents with disability offset.

\section{Factors Associated with Prevalence of Loneliness}

In the fully adjusted model (Model 2) for substantial loneliness, significantly increased risk of loneliness was associated with: younger age; female gender; greater financial strain; not 
owning/purchasing your home; being unemployed or not in the labour force; and living alone or in 'other' living arrangements (effect sizes for all covariates for substantial loneliness are presented in Supplementary Table 3). We repeated the fully adjusted model for exposure to moderate and substantial loneliness for each functional limitation category, comparing respondents with persistent disability and those with no disability (Supplementary Table 4). All functional limitations were associated with significantly increased risk of loneliness. There were very few significant differences in effect size between functional limitation categories.

\section{Association between Disability and Loneliness with Health Status}

Results of the multivariate analyses are presented in Table 2. Regarding mental health, there were highly significant, strong, dose-dependent relationships (main effects) between increased levels of loneliness and poorer mental health. In addition, for both measures there were highly significant relationships between disability status and poorer mental health that mirrored the relationship with physical health (strongest for persistent disability, followed by disability onset, followed by disability offset). However, the differences between groups were not necessarily statistically significant. Finally, for both measures there were significant interactions between disability status and level of loneliness regarding mental health status.

[insert Table 2]

Regarding the dependent variable physical health (SF-12 physical health component), there was an unexpected weak but significant association between substantial loneliness and better self-reported physical health. Exposure to moderate loneliness was unrelated to physical health. Disability status was strongly related to poorer physical health, with a significantly stronger association for persistent disability than disability onset, which in turn had a significantly stronger association than disability offset. There was also a significant disability by loneliness interaction.

The significant interaction effects suggest that disability status may moderate the association between loneliness and mental health. The nature of these interactions was explored through 
inspection of estimated marginal means (Figure 1). As can be seen, for all measures, the difference between the persistent disability and no disability groups increased with exposure to greater levels of loneliness.

[insert Figure 1]

\section{Discussion}

\section{Main findings of this study}

Rates of exposure to substantial loneliness were $25.4 \%(95 \% \mathrm{Cl} 23.5 \%-27.3 \%)$ among adults with persistent disability, $15.4 \%$ among adults with disability onset, $12.3 \%$ among adults with disability offset and 6.9\% (6.5\%-7.3\%) among adults with no disability. Exposure to loneliness was positively associated with the incidence (GHQ-12) and prevalence (SF-12MCS) of mental health problems, but not the prevalence of physical health problems. Disability status appeared to moderate the association between loneliness and mental health, with the difference between the persistent disability and no disability groups increasing with exposure to greater levels of loneliness.

\section{What is already known on this topic}

Previous research has suggested that being lonely can have a detrimental impact on physical and mental health.[3-9] Higher levels of loneliness have been reported among: women; younger adults; those not living in a couple relationship, living alone, and without children; and people who are unemployed.[36, 37] The only population-based study to investigate the association between disability and loneliness suggested that adults with disability may be at much greater risk of exposure than adults without disability.[21]

\section{What this study adds}

Our research adds to the existing literature in four important ways. First, it quantifies the risk of adults with disability in the UK being exposed to loneliness (over 5 times more likely for 'substantial' Ioneliness for those with persistent disability), and how this varies with changes in disability status. 
Second, our results suggest that a substantial part of the increased risk of exposure to loneliness among people with disability can be explained by differential exposure to potentially modifiable risk factors for loneliness such as financial strain, being unemployed or not in the labour force, and living alone. These observations are consistent with the notion that effectively addressing social and economic disadvantage for people with disability may reduce loneliness and improve wellbeing. Third, the association between exposure to loneliness and mental health is stronger among people with persistent disability and disability onset than among the non-disabled population. The latter finding suggests that not being lonely may significantly reduce risk of developing mental health problems following disability onset. Finally, our results add to the limited literature on the association between disability dynamics and health and wellbeing.[38-40]

\section{Limitations of this study}

There are two main limitations of the study that need to be considered. First, the analyses of the association between loneliness and health are cross sectional. As such, it is not possible to separate out temporal relationships between variables or identify causal pathways. Second, Understanding Society is based on a general household sample and does not contain any 'reasonable accommodations' to the interview process to include people with significant disability. As such, it will exclude people with disability living in institutional settings and people whose functional limitations preclude them from participating in a structured interview.

\section{Future Research}

We found that younger adults (16-29 years) experienced the highest rates of substantial loneliness. Future research involving young people with disability is important to understand the development and prevention of chronic loneliness. Longitudinal loneliness data from future waves of Understanding Society will enable examination of the temporal stability of loneliness among people with disability. Future research is required to determine the causal pathways linking loneliness and changes in health among people with disability, a substantial and frequently marginalised segment 
of the population. Such studies could include intervention research examining the effects on loneliness of modifying environmental factors, such as employment, living arrangements and financial strain.

\section{Funding}

The research was supported by Australian National Health and Medical Research Council grant APP1116385.

\section{Conflicts of Interest}

None declared

\section{Key Points}

- Being lonely can have a detrimental impact on physical and mental health.

- Adults with persistent disability were over 5 times more likely to experience substantial levels of loneliness than people with no disability.

- For people with disability, the strength of the association between exposure to loneliness and mental health problems was greater than that observed among the non-disabled population.

\section{References}

1 Berkman LF, Krishna A. Social network epidemiology. In: Berkman LF, Kawachi I, Glymour MM, eds. Social Epidemiology. Oxford: Oxford University Press 2014:234-89.

2 Shoham DA, Messer LC. Social network analysis for epidemiology. In: Oakes JM, Kaufman JS, eds. Methods in Social Epidemiology (2nd Edition). San Francisco: Josey Bass 2017:212-38.

3 Hawkley LC, Cacioppo JT. Loneliness matters: A theoretical and empirical review of consequences and mechanisms. Annals of Behavioral Medicine 2010;40:218-27. 

health consequences of social isolation and loneliness. Public Health 2017;152:157-71.

5 Holt-Lunstad J, Smith TB, Baker M, et al. Loneliness and Social Isolation as Risk Factors for Mortality: A Meta-Analytic Review. Perspectives on Psychological Science 2015;10:227-37.

6 Wang J, Mann F, Lloyd-Evans B, et al. Associations between loneliness and perceived social support and outcomes of mental health problems: a systematic review. BMC Psychiatry 2018;18. 7 Mihalopoulos C, Le LK, Chatterton ML, et al. The economic costs of loneliness: a review of cost-of-illness and economic evaluation studies. Social Psychiatry and Psychiatric Epidemiology https://doiorg/101007/s00127-019-01733-7 2019 online.

8 Petitte T, Mallow J, Barnes E, et al. A systematic review of loneliness and common chronic physical conditions in adults. Open Psychology Journal 2015;8:113-32.

9 National Academies of Sciences E, and Medicine, . Social Isolation and Loneliness in Older Adults: Opportunities for the Health Care System https://doi.org/10.17226/25663. Washington, DC: The National Academies Press 2020.

10 Valtorta NK, Kanaan M, Gilbody S, et al. Loneliness and social isolation as risk factors for coronary heart disease and stroke: systematic review and meta-analysis of longitudinal observational studies. Heart 2016:1009-16.

11 World Health Organization. Rio Political Declaration on Social Determinants of Health (http://www.who.int/sdhconference/declaration/en/). Geneva: World Health Organization 2011. 12 Institute for Health Equity. Health Equity in England: The Marmot Review 10 Years On. London: UCL: Institute for Health Equity 2020.

13 Emerson E, Madden R, Graham H, et al. The health of disabled people and the social determinants of health. Public Health 2011;125:145-7.

14 Krahn G, Walker DK, Correa-De-Araujo R. Persons with disabilities as an unrecognized health disparity population. American Journal of Public Health 2015;105:S198-S206. 
15 Department for Work and Pensions. Fulfilling Potential: Building a deeper understanding of disability in the UK today. London: Department for Work and Pensions 2013.

16 Office for Disability Issues. Experiences and Expectations of Disabled People: A research report for the Office for Disability Issues. London: Office for Disability Issues 2008.

17 Equality and Human Rights Commission. Being Disabled in Britain: A journey less equal. London: Equality and Human Rights Commission 2017.

18 Australian Government. Shut Out: The experience of people with disabilities and their families in Australia. National Disability Strategy consultation report. Canberra: Australian Government Publishing Service 2009.

19 Mithen J, Aitken Z, Ziersch A, et al. Inequalities in social capital and health between people with and without disabilities. Social Science \& Medicine 2015;126:26-35.

20 Emerson E, Llewellyn G, Honey A, et al. Lower well-being of young Australian adults with self-reported disability reflects their poorer living conditions rather than health issues. Australian \& New Zealand Journal of Public Health 2012;36:176-82.

21 Redacted to preserve anonymity of authors. 2020.

22 Emerson E, Honey A, Llewellyn G. Disability Transitions Across The Life-Course: Preliminary Data From AustraliaDisability Transitions Across The Life-Course: Preliminary Data From Australia (<http://sydney.edu.au/health-sciences/cdrp/pdfs/working-paper-1-2013-transitions.pdf> ). Sydney: Centre for Disability Research and Policy: University of Sydney 2013.

23 Office for National Statistics. Life Opportunities Survey: Wave Three, Final Report, October 2012 to September 2014. Newport: Office for Ntaional Statistics 2015.

24 University of Essex. Institute for Social and Economic Research, NatCen Social Research, Kantar Public. Understanding Society: Waves 1-9, 2009-2018 and Harmonised BHPS: Waves 1-18, 1991-2009. 12th edition. UK Data Service. SN: 6614 http://dx.doi.org/10.5255/UKDA-SN-6614-13 2019. 
25 Buck N, McFall SL. Understanding Society: design overview. Longitudinal and Life Course Studies 2012;3:5-17.

26 Carpenter H. UK Household Longitudinal Study: Wave 9 technical report. London: Kantar, Publc Division 2019.

27 Institute for Social and Economic Research. Understanding Society: The UK Household Longitudinal Study Waves 1-9, User Guide. Colchester, Essex: Institute for Social and Economic Research, University of Essex 2019.

28 Hughes ME, Waite LJ, Hawkley LC, et al. A Short Scale for Measuring Loneliness in Large Surveys: Results From Two Population-Based Studies. Research in Aging 2004;26:655-72.

29 Department for Digital Culture Media and Sport. A connected society A strategy for tackling loneliness - laying the foundations for change. London: Department for Digital, Culture, Media and Sport 2018.

30 Ware JE, Kosinski M, Keller SD. SF-12: How to Score the SF- 12 Physical and Mental Health Summary Scales. Boston: The Health Institute, New England Medical Center 1996.

31 Ware JE, Kosinski M, Keller SD. A 12-Item Short-Form Health Survey (SF-12): Construction of scales and preliminary tests of reliability. Medical Care 1996;32:220-33.

32 Gandek B, Ware JE, Aaronson NK, et al. Cross-Validation of Item Selection and Scoring for the SF-12 Health Survey in Nine Countries: Results from the IQOLA Project. Journal of Clinical Epidemiology 1998;51:1171-78.

33 Goldberg D, Gater R, Sartorius N, et al. The validity of two versions of the GHQ in the WHO study of mental illness in general health care. Psychological Medicine 1997;27:191-7.

34 Goldberg D, Williams P. A Users Guide to the General Health Questionnaire. Windsor: NFERNelson 1988.

35 Knol MJ, Le Cessie S, Algra A, et al. Overestimation of risk ratios by odds ratios in trials and cohort studies: alternatives for logistic regression. Canadian Medical Association Journal 2012;184:895-9. DOI:10.1503/cmaj.101715. 
36 Office for National Statistics. Loneliness - What characteristics and circumstances are associated with feeling lonely? Newport: Office for National Statistics 2018.

37 Beutel M, Klein E, Brähler E, et al. Loneliness in the general population: Prevalence, determinants and relations to mental health. BMC Psychiatry 2017.

38 Emerson E, Kariuki M, Honey A, et al. Becoming Disabled: The Association between Disability Onset in Younger Adults and Subsequent Changes in Productive Engagement, Social Support, Financial Hardship and Subjective Wellbeing Disability \& Health Journal 2014;7:448-56.

39 Kariuki M, Honey A, Emerson E, et al. Mental health trajectories of young people after disability onset. Disability and Health Journal 2011;4:91-101.

40 Lucas RE. Long-Term Disability Is Associated With Lasting Changes in Subjective Well-Being: Evidence From Two Nationally Representative Longitudinal Studies. Journal of Personality and Social Psychology 2007;92:717-30. 


\begin{tabular}{|c|c|c|c|c|}
\hline Analysis & Group & Low Loneliness & $\begin{array}{l}\text { Moderate } \\
\text { Loneliness }\end{array}$ & $\begin{array}{r}\text { Substantial } \\
\text { Loneliness }\end{array}$ \\
\hline \multirow{5}{*}{$\begin{array}{l}\text { Derived ordinal } \\
\text { measure of loneliness } \\
\qquad x 2=1068.1(6) \\
p<0.001\end{array}$} & $\begin{array}{l}\text { Persistent disability } \\
\text { (W8 and W9) }\end{array}$ & $\begin{array}{r}36.3 \% \\
(34.2 \%-38.4 \%) \\
\end{array}$ & $\begin{array}{r}38.3 \% \\
(36.2 \%-40.4 \%) \\
\end{array}$ & $\begin{array}{r}25.4 \% \\
(23.5 \%-27.3 \%) \\
\end{array}$ \\
\hline & $\begin{array}{l}\text { Disability onset } \\
\text { (W9 only) }\end{array}$ & $\begin{array}{r}47.6 \% \\
(44.7 \%-50.5 \%) \\
\end{array}$ & $\begin{array}{r}37.0 \% \\
(34.2 \%-39.8 \%) \\
\end{array}$ & $\begin{array}{r}15.4 \% \\
(13.3 \%-17.5 \%) \\
\end{array}$ \\
\hline & $\begin{array}{l}\text { Disability offset } \\
\text { (W8 only) }\end{array}$ & $\begin{array}{r}55.0 \% \\
(51.7 \%-58.5 \%) \\
\end{array}$ & $\begin{array}{r}32.7 \% \\
(29.6 \%-35.8 \%) \\
\end{array}$ & $\begin{array}{r}12.3 \% \\
(10.1 \%-14.5 \%) \\
\end{array}$ \\
\hline & No disability & $\begin{array}{r}66.0 \% \\
(65.2 \%-66.8 \%) \\
\end{array}$ & $\begin{array}{r}27.1 \% \\
(26.3 \%-27.9 \%) \\
\end{array}$ & $\begin{array}{r}6.9 \% \\
(6.5 \%-7.3 \%) \\
\end{array}$ \\
\hline & Total & $\begin{array}{r}60.7 \% \\
(60.0 \%-61.4 \%) \\
\end{array}$ & $\begin{array}{r}29.3 \% \\
(30.0 \%-38.4 \%) \\
\end{array}$ & $\begin{array}{r}10.0 \% \\
(9.6 \%-10.5 \%) \\
\end{array}$ \\
\hline \multirow[t]{3}{*}{$\begin{array}{l}\text { Adjusted PRRs } \\
\text { Model } 1\end{array}$} & Persistent disability & 1.0 & $\begin{array}{r}1.93^{* * *} \\
(1.83-2.04) \\
\end{array}$ & $\begin{array}{r}5.16^{* * *} \\
(4.71-5.65) \\
\end{array}$ \\
\hline & Disability onset & 1.0 & $\begin{array}{r}1.56^{* * *} \\
(1.45-1.96) \\
\end{array}$ & $\begin{array}{r}2.77^{* * *} \\
(2.40-3.19) \\
\end{array}$ \\
\hline & Disability offset & 1.0 & $\begin{array}{r}1.35^{* * *} \\
(1.22-1.49) \\
\end{array}$ & $\begin{array}{r}2.06 * * * \\
(1.71-2.48) \\
\end{array}$ \\
\hline \multirow[t]{3}{*}{$\begin{array}{l}\text { Adjusted PRRs } \\
\text { Model } 2\end{array}$} & Persistent disability & 1.0 & $\begin{array}{r}1.58^{* * *} \\
(1.49-1.69) \\
\end{array}$ & $\begin{array}{r}2.89 * * * \\
(2.58-3.32) \\
\end{array}$ \\
\hline & Disability onset & 1.0 & $\begin{array}{r}1.43^{* * *} \\
(1.32-1.54) \\
\end{array}$ & $\begin{array}{r}2.21^{* * *} \\
(1.92-2.54) \\
\end{array}$ \\
\hline & Disability offset & 1.0 & $\begin{array}{r}1.20 * * * \\
(1.09-1.33)\end{array}$ & $\begin{array}{r}1.61^{* * *} \\
(1.33-1.94)\end{array}$ \\
\hline
\end{tabular}




\begin{tabular}{|c|c|c|c|c|c|c|}
\hline \multirow[b]{3}{*}{$\begin{array}{l}\text { Independent } \\
\text { Variables }\end{array}$} & \multicolumn{6}{|c|}{ Dependent Variables } \\
\hline & \multicolumn{2}{|c|}{ SF-12 Physical } & \multicolumn{2}{|c|}{ SF-12 Mental } & \multicolumn{2}{|c|}{ GHQ-12 } \\
\hline & $\mathrm{B}(95 \% \mathrm{Cl})$ & $\begin{array}{l}\text { Wald Chi- } \\
\text { Sq(df)/p }\end{array}$ & $\mathrm{B}(95 \% \mathrm{Cl})$ & $\begin{array}{l}\text { Wald Chi- } \\
\text { Sq(df)/p }\end{array}$ & $\mathrm{B}(95 \% \mathrm{Cl})$ & $\begin{array}{l}\text { Wald Chi- } \\
\text { Sq(df)/p }\end{array}$ \\
\hline $\begin{array}{r}\text { Persistent } \\
\text { Disability } \\
\end{array}$ & $\begin{array}{l}-15.08 \\
(-14.48-15.68)\end{array}$ & $2430.6(1)^{* * *}$ & $\begin{array}{l}-3.42 \\
(-2.72-4.12)\end{array}$ & $91.8(1)^{* * *}$ & $\begin{array}{l}+0.96 \\
(+0.74+1.18)\end{array}$ & $74.9(1)^{* * *}$ \\
\hline $\begin{array}{r}\text { Disability } \\
\text { onset }\end{array}$ & $\begin{array}{l}-7.80 \\
(-7.12-8.48)\end{array}$ & $510.5(1)^{* * *}$ & $\begin{array}{l}-2.03 \\
(-1.24-2.82)\end{array}$ & $25.5(1)^{* * *}$ & $\begin{array}{l}+0.79 \\
(+0.55+1.04)\end{array}$ & $39.9(1)^{* * *}$ \\
\hline $\begin{array}{r}\text { Disability } \\
\text { offset }\end{array}$ & $\begin{array}{l}-3.64 \\
(-2.92-4.37) \\
\end{array}$ & $95.9(1)^{* * *}$ & $\begin{array}{l}-1.58 \\
(-0.72-2.43) \\
\end{array}$ & $13.2(1)^{* * *}$ & $\begin{array}{l}+0.31 \\
(+0.04+0.57)\end{array}$ & $5.2(1)^{*}$ \\
\hline $\begin{array}{r}\text { No disability } \\
\text { (reference } \\
\text { group) }\end{array}$ & 0 & & 0 & & 0 & \\
\hline $\begin{array}{l}\text { Loneliness: } \\
\text { Substantial }\end{array}$ & $\begin{array}{l}+0.95 \\
(+0.41+1.49)\end{array}$ & $11.6(1)^{* *}$ & $\begin{array}{l}-12.85 \\
(-12.22-13.48)\end{array}$ & $1597.5(1)^{* * *}$ & $\begin{array}{l}+3.59 \\
(+3.39+3.78)\end{array}$ & $1283.3(1)^{* * *}$ \\
\hline $\begin{array}{l}\text { Loneliness: } \\
\text { Moderate }\end{array}$ & $\begin{array}{l}-0.02 \\
(-0.33+0.29)\end{array}$ & $0.0(1)$ & $\begin{array}{l}-6.56 \\
(-6.20-6.92)\end{array}$ & $1273.9(1)^{* * *}$ & $\begin{array}{l}+1.40 \\
(+1.29+1.51)\end{array}$ & $598.9(1)^{* * *}$ \\
\hline $\begin{array}{r}\text { Loneliness: } \\
\text { Low } \\
\text { (reference } \\
\text { group) }\end{array}$ & 0 & & 0 & & 0 & \\
\hline $\begin{array}{r}\text { Disability by } \\
\text { Loneliness } \\
\text { interaction }\end{array}$ & & $26.9(6) * * *$ & & $46.1(6)^{* * *}$ & & $79.0(6)^{* * *}$ \\
\hline \multicolumn{7}{|c|}{$\begin{array}{l}\text { Notes: }{ }^{*} p<0.05 * * p<0.01 * * * p<0.001 \\
\text { Models also adjusted for participant age, gender, ethnicity, living alone, living as a couple, household income } \\
\text { poverty, low access to consumer durables, self-reported financial strain, home ownership and employment } \\
\text { status }\end{array}$} \\
\hline
\end{tabular}


Figure 1: Estimated marginal means (with $95 \% \mathrm{Cl}$ ) of physical and mental health scores at W9 by disability status and level of loneliness for GHQ-12 score (upper panel), SF-12 Mental Component Score (middle panel) and SF-12 Physical Component Score (lower panel) 

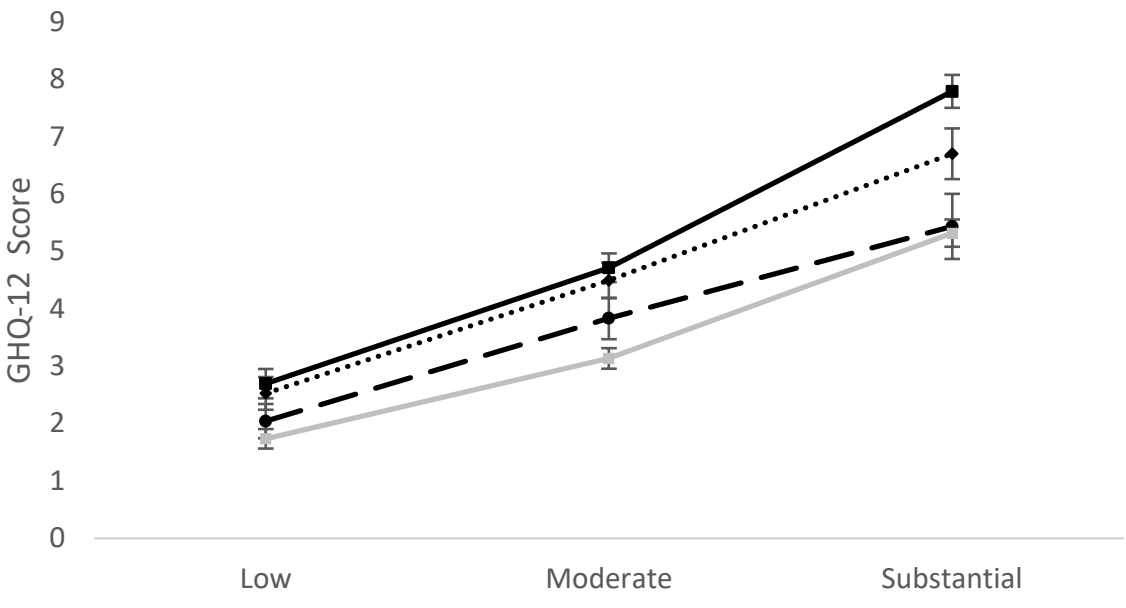

Loneliness category
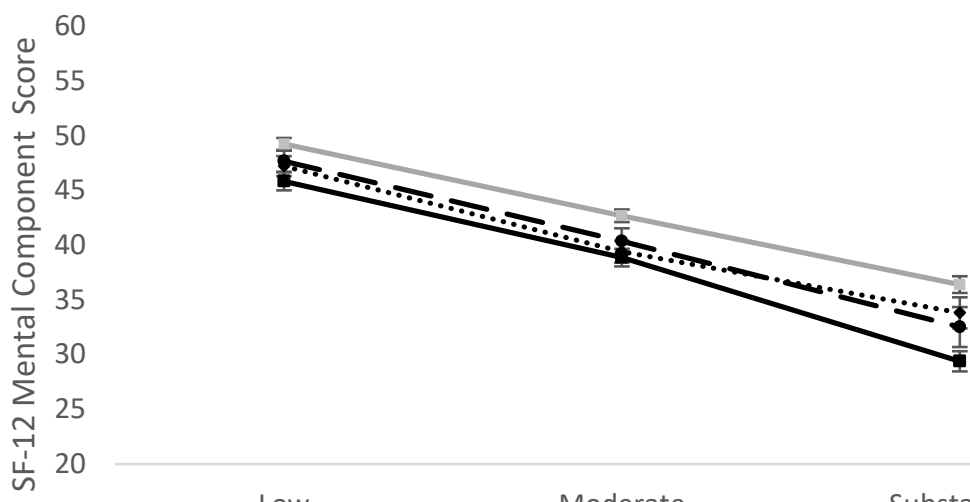

Low
Loweliness category
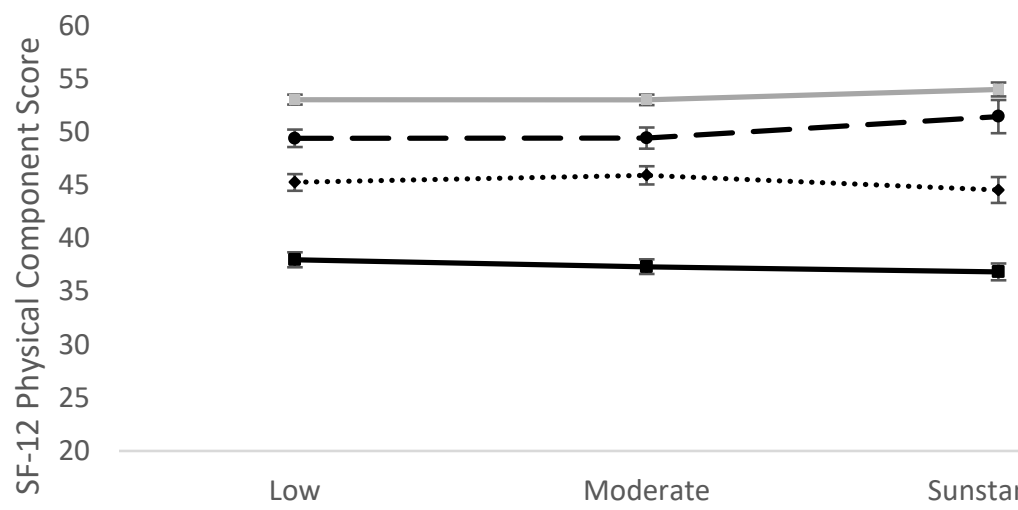

은 30

孚 25

芒 20 